\title{
The Enlightenment of Residential College System to the Construction of Academy System in Universities in China-The Study of Jinan
}

\author{
Yuhong Zhou \\ School of Public Administration and Emergency Management, Jinan University, Guangzhou, China \\ Email: 18819465032@163.com
}

How to cite this paper: Zhou, Y. H. (2020). The Enlightenment of Residential College System to the Construction of Academy System in Universities in China-The Study of Jinan. Open Journal of Social Sciences, 8 , 96-107.

https://doi.org/10.4236/jss.2020.84007

Received: March 9, 2020

Accepted: April 7, 2020

Published: April 10, 2020

Copyright $\odot 2020$ by author(s) and Scientific Research Publishing Inc. This work is licensed under the Creative Commons Attribution International License (CC BY 4.0).

http://creativecommons.org/licenses/by/4.0/

\begin{abstract}
With the popularization of Higher Education, Chinese universities reform the training mode of talents actively, to improve the quality of talents training. In this context, some universities in China have carried out the academy system reform one after another. The academy system not only inherits the spirit of ancient Chinese academies, but also borrows the model of residential college system of top universities in Britain and the United States becomes an important practice of higher education personnel training. This paper combs the historical evolution of residential college system and Chinese academy system, and on the basis of analyzing the practice of Jinan University, puts forward some corresponding suggestions.
\end{abstract}

\section{Keywords}

Academy System, Residential College System

\section{Introduction}

Since the college expansion at the end of last century, China has gradually entered the stage of higher education popularization, and the enrollment rate of higher education has been rising. The expansion of university enrollment has brought the country a large talent pool of college students, but it has also been accompanied by many doubts. Many voices believe that the expansion of university enrollment has lowered the quality of college education, and that the old elite-style education has fallen apart. "What kind of talents to cultivate and how to cultivate talents" has always been the central topic in the development of education. The former view of talents has changed, and the all-round development of innovative talents has become the demand of society, it has also become 
the goal of higher education. Each university has carried on the different education reform exploration, shifts the center of gravity to the student, changes "teacher-based" to "student-based". Since the founding of Fudan Academy in 2005, many universities in mainland China have tried to carry on the academy system reform, that is, to inherit the cultural spirit of our traditional academy, to learn from the residential college system, resulting in a new student management model. It cannot be denied that this kind of exploration is worth encouraging. Through the practice and research of several colleges and universities, we can see that this model is trying to make up for the shortage of traditional education, paying more attention to the improvement of students' comprehensive ability and the independent development of their personality. However, there are some problems in the planning and implementation of colleges and universities, and the analysis of them is helpful for us to provide experience and advice for the development of academy system.

Jinan University established the "Four Seas College" in 2010. It's an experimental field as a mode of talent cultivation, which is a practical exploration of cultural innovation of characteristic academy. There are still many problems in the operation of Four Seas College. This paper combs the historical evolution of residential college system and Chinese academy system, and on the basis of analyzing the practice of Jinan University, puts forward some corresponding suggestions.

\section{Residential College System and Academy System}

\subsection{Residential College System}

Residential college system is a kind of student management mode with a long history, which originated from England. Some scholars think it originated from Oxford University, and that it has been practiced since Oxford founded the school, while some scholars support the idea that it began at Cambridge and evolved in the 13th century after Bishop Erie took in 12 Oxford's students and teachers. The jury is still out, on the origins of Oxford and Cambridge, it actually delineates the approximate time frame for the formation of residential college system, which is generally believed to be between the 13th and 16th centuries.

There are now two dimensions to Oxford's organization structure: one is academic, divided into departments by major, and the other is administrative, divided into 38 colleges (with no students at All Souls). Every faculty member and every student belongs equally to a department and a college. The most striking feature of this two-track system is the decentralization of power, with individual colleges responsible for their own funding, teaching and research, much like a federal system of state government.

The teaching and research activities of the University of Oxford (especially the latter) are mainly organized by the department of studies, which is not an autonomous unit within the university. They are all inter-collegiate bodies and are not attached to any one college, but the faculty and students of each department 
must be a member of one of the colleges at Oxford firstly. And students will conduct accommodation, meals, social activities in the college, of course, there is no lack of learning. Crucially, Oxford's college is not segregated by major, and each college has students from several different departments, such as literature and mechanics, who may live next door to each other, in this way they naturally intercommunicate across disciplines. Another benefit of the college system is that it is easier to feel a sense of belonging in a small community. Oxford is a university with more than 20,000 students, compared with a few hundred at each college. They came from different professions, but on the whole a college has its own characteristics, for example, the Church of Christ college with a strong aristocratic atmosphere, Merton college produced a number of poets; St Edmunds Hall College has a strong interest in recruiting athletes; Aurill College focuses on training pastors; and Modrin College has many master rowers (Cao, 2009). Students can choose a college that matches their temperament and interests, and it is often easier to bond with the college.

The existence of the residential college system provided the soil for the development of "the jewel of Oxford's crown" the tutorial system. Some scholars do not refer to tutorial system when they expound residential college system, while others hold that tutorial system is an important part of residential college system.

In view of the implementation of the tutorial system, in order to achieve the result of "all-inclusive tutors", many tutors, live in the college and become part of the college or student community, therefore, the thesis holds that the tutorial system is actually an important part of the residential college system. The tutorial system focuses on personal contact and face-to-face communication. Every week undergraduates meet with tutors in groups or alone. Students need to prepare in advance, through reading the instructor assigned books, materials to complete last week's assignment, usually a small paper. During the one-hour meeting, the tutor answers questions and discusses the problems in the student's thesis. The tutor is also responsible for the students on the professional examination. Many tutors and students live together in the residential college to provide more opportunities for exchanges between teachers and students. Students are exposed to such an environment and can not only learn knowledge but also have a correct attitude and improve quality. The tutorial system with deep communication is an organic supplement to the traditional teaching system, which has an imperceptible influence on shaping students' knowledge system and the cultivation of their individual thinking ability.

In the 20th century, Yale and Harvard, faced with their own development difficulties, both chose to introduce residential college system and gradually developed their own characteristics. Yale has a variety of facilities, students can apply for admission to the college, in general, schools assign students from different backgrounds to different colleges. The college has a corresponding management organization to serve the students, with dean, academician, management secretary, graduate assistant, student administrator, college representative, in charge 
of different work to provide advice and assistance to students. Each residential college has a board of directors responsible for the planning and organization of various social and recreational activities, academic seminars (Liu, 2010). The dormitory of the Harvard offers tutoring, small classes and seminar-style learning for teachers and students, as well as social services, performances, concerts, lectures, special banquets and parties, intramural competitions of various sports teams, etc. Students have ample opportunities to participate in peer-to-teacher exchanges, and dormitories serve an important informal education function. The dormitory also houses wardens, tutors, professors and administrators from other universities, as well as visiting scholars, who participate in student guidance and services (He, 2016).

In modern times, Western colleges and universities have their own distinctive brand of residential college system in each school, each with its own emphasis, but there are some common features: dormitories are not only to provide students with rest, but also like a community, in which students' learning, living, social needs and so on can be met. The school adopts the dual-track management system, residential colleges and departments have their own labor, managing both teachers and students. Tutorial System gives students personalized guidance. There are sound and rich hardware facilities, a variety of Cultural and sports activities with a special management staff, each in their respective roles.

\subsection{Academy System}

The academy system is a kind of student apartment as the carrier of Education, through the general education or what we usually call the liberal education and the student's professional education to achieve integration and balanced development, student education management system aiming at cultivating all-round developing talents (Liu, 2017). In addition to the residential college system, General Education is an integral part of academy-style education. Because of historical reasons, Hong Kong, Macao and Taiwan were influenced by western education, and early on they began to implement the academy system in combination with the reform of general education, established a relatively stable operating mode. Among them, the Chinese University of Hong Kong is the first university to carry out the academy system reform, and its results are widely recognized in the world. Similar cultural and educational traditions make the experience worth learning for mainland universities.

"Tracing the teaching spirit of the song and Ming academies, adopting the tutorial system of western universities, the academy is to communicate eastern and western cultures with the purpose of humanism education, and to seek the future for the well-being of mankind in a peaceful society" (Qian, 2004) this was the philosophy when the New Asia College of the Chinese University of Hong Kong founded. The New Asia College is also one of the earliest colleges in Hong Kong. Mr. Qian argues that the tutorial system is designed to reduce the teacher-student divide, with students focusing only on credits and diplomas. The tutorial system in the Chinese University of Hong Kong is similar to that in west- 
ern universities. In the "New Asian academic discipline", there is a "You must first for a person, and then to become an expert." The college stressed the importance of general education. New students should study basic subjects such as language and mathematical logic firstly, and then choose a specialized subject according to their interests. The New Asia College also encourages the exchange of arts and sciences, encourages students of arts to study economics, and encourages students of business economics to improve their literary culture. This kind of general education has a great positive effect on improving the communication between teachers and students, promoting the all-round development of students, and making up for the defects of professional education.

At the beginning of the 21st century, with the changes of political, economic and cultural exchanges at home and abroad, a series of reforms are brewing in the field of higher education to meet the requirements of talents training in the new era. In 2005, Fudan University established Fudan College, which took the lead in the reform of the academy system throughout the country. In the same year, the Xi'an Jiaotong University began a pilot project, and the academy system was formally reformed in the new semester of 2006. In 2007, East China Normal University Meng Xiancheng College was established, as a specialized institution for undergraduate normal school students. In 2008, the Shantou University and other institutions of higher learning were also reformed. The attempt of academy system spread gradually in China.

\section{Introduction of Four Seas College}

In order to carry out the reform of the talent training mode, ensure the normal development of the teaching and student management of the freshmen, and cultivate the freshmen's belonging and honor, the Jinan University established the "Four Seas College" in July 2010. So far, nearly 5,000 overseas Chinese and foreign students have been trained. In fact, Four Seas College is an experimental field as a mode of talent cultivation, which is a practical exploration of cultural innovation of characteristic academy. Under the college, there are four divisions, the center for teaching research and reform, the center for learning and development, the center or student expansion and development, and the center for student culture and creativity, committed to the cultivation of the six capabilities (knowledge, psychology, culture, Innovation, sports, teamwork).

\subsection{Building a Student Community}

According to Harvard's Lowell, "Character of students depends not only on the education they receive, but also on the atmosphere of the good company in which they live to a large extent". He attached great importance to the status of student dormitories. during his tenure, Lowell established 13 residential colleges, so that almost all undergraduate students live in dormitories. As the old saying goes, "Lies down with dogs must rise up with fleas." Today, "Peer Education" is all closely related. The community-based management of students is the charac- 
teristic of the academy system. In the Four Seas College, we advocate students' self-education, self-management and self-service. It not only gives students a chance to improve their culture in the community, but also brings students closer to each other. In Management, Four Seas College divides its new students into several classes each year, with academic tutors, counselors and teaching assistants.

Four Seas College has a rich variety of cultural and sports activities. A search of its website and the wechat account of the "Students' Union of the Four Seas College" reveals a number of its signature activities: The Four Seas Lecture, the Four Seas Carnival, Chinese Talent Training, the Chinese Cultural Quiz Show, the Student Cadres Elementary Training Courses, and so on. ThE activities balance both knowledge and interest, and pay attention to the dissemination of Chinese culture showing in Figure 1 and Figure 2.

It should be noted that Four Seas College is mainly responsible for undergraduates coming beyond the inland for the general education stage, after the end of freshman year, students will no longer belong to the college and will go to their

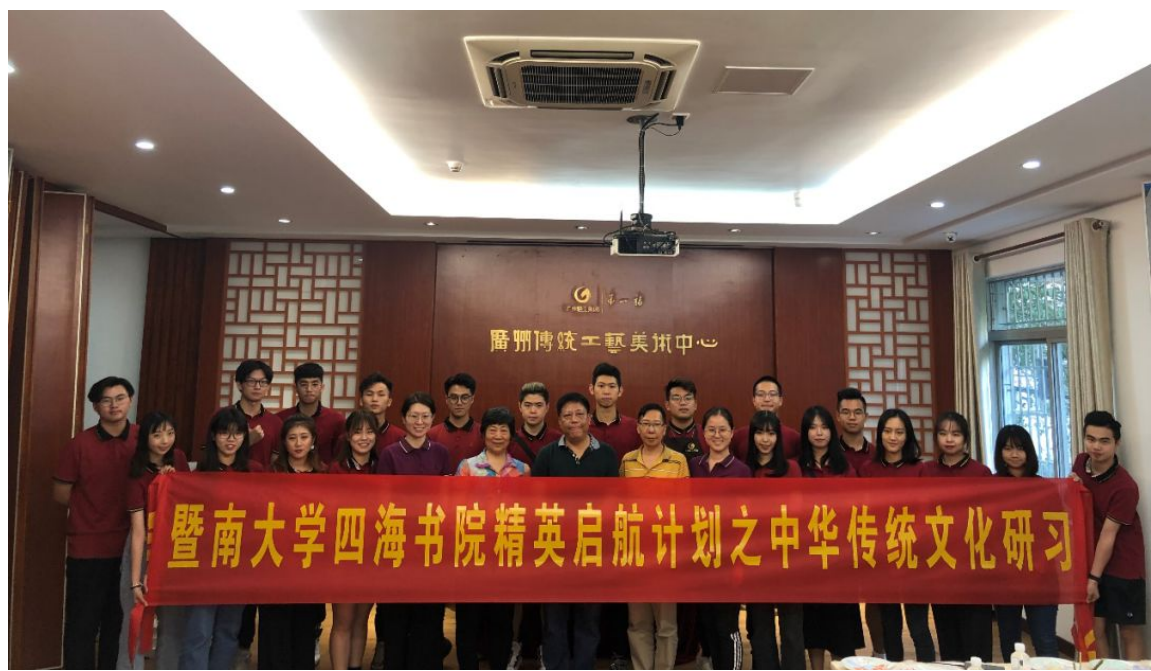

Figure 1. Chinese traditional culture course for students of Four Seas College.

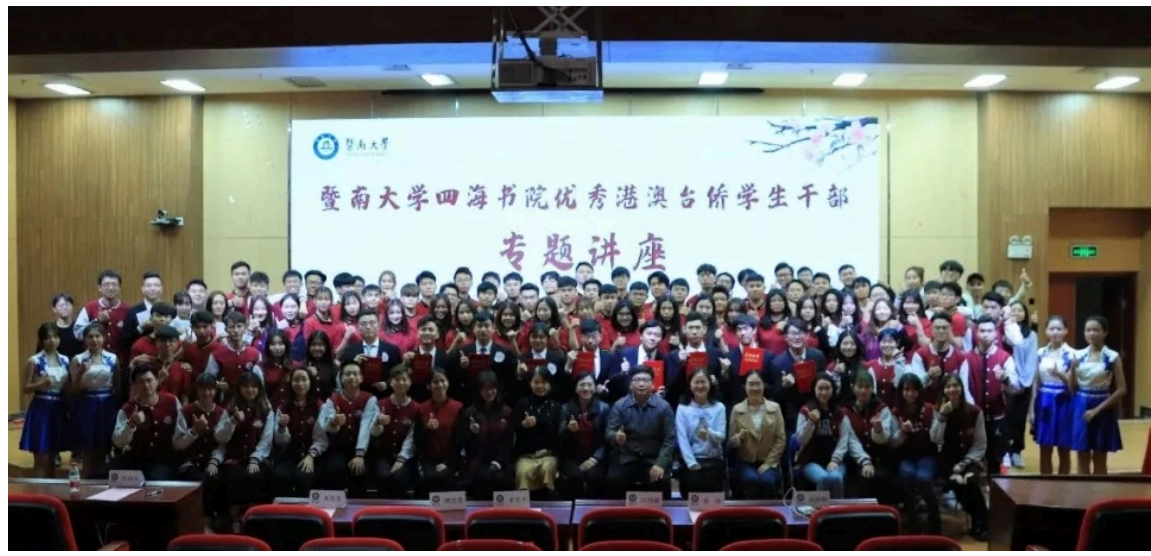

Figure 2. The student cadres elementary training courses. 
respective professional colleges. The high mobility of students is a major obstacle to the building of close relationships in the student community. When Students enter college, they know they will leave after one year. It is difficult to develop a sense of belonging to the college in a short time.

\subsection{General Education}

The Four Seas College is responsible for the management of teaching and students of general education for undergraduates coming beyond the inland, including only the first year students. After the end of the first year, students choose their major again, so it is also known as Freshman College. The curriculum system of Four Seas College includes general education curriculum and basic education curriculum, general education curriculum includes compulsory curriculum and elective curriculum. The general education compulsory course is a common compulsory course for students from Hong Kong, Macao and Taiwan with different academic backgrounds, including language intensive courses, mathematical culture and thinking, education in national conditions, information technology and physical education. The general education elective course is made up of the general introduction course of the subject, aiming at systematically introducing the current situation and development trend of the subject, at the same time, it introduces the setting situation and development prospect of each major in this subject, which is helpful for them to understand the value of different disciplines and guide the students to choose the major.

However, in practice, students are not active in learning, and the serious situation of failing and partial courses has not been solved. In "the Four Seas College class management and assessment method", the only requirement for an outstanding group is "A grade point average of 2.5 or above for the entire group of students in the academic year". When foreign students are admitted to the school, the learning foundation will indeed be relatively weak. How to improve students' learning enthusiasm and acquire scientific learning methods in the community under the guidance of tutors and students, this is also the problem that Four Seas College needs to solve next.

\subsection{Mentorship}

The Four Seas College also has a very distinct characteristic, has carried out "the whole journey tutorial system". According to the regulations of the school, Four Seas College provides students with tutors, who provide students with education in three aspects: academic guidance, psychological guidance and value-oriented guidance. Students can communicate with most of the instructors by appointment, telephone, Internet, etc. On the college website, the arrangement of instructors for the Four Seas College have been published, it shows that the teacher-student ratios of college is close to 1:50.

The tutorial system is the key to the residential college system, and the Four Seas College has also adopted it in the practice of the academy system. However, 
we can see that there is a situation that too many students are enrolled, mentor ship emphasizes frequent communication and personalized instruction, and it is difficult to achieve. Many universities that have tried the academy system in China have encountered this embarrassment. According to the regulations of Fudan University on the work of undergraduate tutors, the number of tutors and students in other colleges and departments is 1:40, except for individual departments with 1:8, the teacher-student ratio is high. In the Four Seas College, the requirements for tutors and counselors are all general guidance, and there are situations of duplicating functions, when faced with detailed real-life problems, teachers can only "follow the heart".

Four Seas College has been running for nine years since it was founded in 2010. It has accumulated a lot of experience in practice and made some achievements. However, we should pay more attention to the problems that still exist: high mobility of students, difficult emotional maintenance; the student study enthusiasm is not high, the study effect is not good; the teacher-student ratio is too high, the tutorial system has never been effectively implemented. These problems need to be further solved, and the practice of Four Seas College is far from over.

\section{Suggestions}

\subsection{Defining the Objectives and Positioning}

Many scholars have expounded the construction goal of the academy system in detail. Huang (2010) believes that the academy system should be an effective complement to, rather than a substitute for, the traditional college student management model. Tu (2013) believes that the academy system is a positive and meaningful attempt in the cultivation of talents and the management of colleges and universities in China, a supplement to the traditional management system of colleges and universities, and a return to the educational ideas of ancient academies. Many problems emerged under the college system are expected to be improved under the college system. In the new period of educational reform and development, universities are actively exploring new models of personnel training, on the basis of introducing the western model of residential college system, insisting the spirit of the ancient Chinese academies: paying attention to the cultivation of moral character and the relationship between teachers and students, paying attention to the aptitude teaching principle. The more in the "change", the more we must grasp the "unchanged" to correct the direction of reform. What has changed is the mode of student management and the method of operation. What remains constant is the all-round development of the training objectives and people-oriented educational ideology. Try to see enduring patterns in the face of constant change, the university can stand firm in the tide of the times.

Four Seas College first appeared as a trial field for the training mode of talents in Jinan University. It was set up to recruit new undergraduate students, the aim 
is "to ensure the normal running of the teaching and student administration of the new students, and to cultivate the sense of belonging and honor of them". Then we can find the central point of the college's work: the teaching and life management of the new students from non-mainland. Compared with students from mainland, students from non-mainland have several features: weak learning foundation, stronger sense of self-determination, long distance from home, loneliness and cultural barriers make it more difficult for them to integrate into the group. Therefore, when the Jinan University chooses the group of students from non-mainland as the experimental object, it actually chooses the "high difficulty" model, which will face more difficulties than other and universities that carry out the academy system. Therefore, it is more necessary for college instructors and administrators to pay attention to students' physical and mental health, and to spend a lot of energy on communication to maintain and build close teacher-student relationship and student-student relationship.

Where there are difficulties, there will be opportunities. The characteristics of recruiting students from outside not only add difficulties to the management of the academy, but also promote the academy to take a road of its own characteristics: incorporating Chinese cultural elements into its teaching, it should be based on the school-running principle of Jinan University; strengthening students' self-management and self-service consciousness, and promoting the formation of students' self-governing organizations; paying attention to practical teaching, when students have poor basis and wake study motivation, we can try field survey and turn over classroom teaching to improve comprehensive quality and encourage them to develop their strengths and avoid their weaknesses. For the practice of the academy system, we can never copy foreign things blindly or mechanically. It is necessary to pay more attention to the characteristics of students, teaching students in accordance with their aptitude, in order to promote the overall development of students.

\subsection{Well Established Regulations}

The systems are interconnected, and understanding education from the point of view of connection helps us analyzing and solving problems. The reform of the academy system in China's mainland has just started, is still in the experimental stage, many systems are not perfect yet, the existing basic provisions also exist problems such as ambiguity, cross-functional. The published responsibility of the mentor has a vague definition, there is no quantitative indicators, no accurate evaluation of teachers' work, so the supervisory role is not strong. In the academy system, which is a new type of student management mode, teachers' selection and employment requirements, evaluation mechanism and promotion mechanism should be adjusted accordingly to ensure that they have equal promotion opportunities with other teachers.

First, there is a need to rationalize the responsibilities of the existing departments and teachers: the centre for teaching research and reform is responsible 
for the management of the teaching and mentoring; the center for learning and development is responsible for the effective learning of the college's students, the center for student expansion and development is responsible for all aspects of the college's education in entrepreneurship and Innovation; the center for student culture and creativity is responsible for guiding students to develop various cultural and creative activities. It is necessary for academic tutors and counselors to cooperate closely to focus on students' study and ideological life. In the student work, the student should establish the main body status to the teacher appraisal. Under the academy system, the tutor is the teacher who has the closest contact with the students. The feedback from students is a testament to the work of the tutors, not the text handed in during the examination, therefore, there should be a special evaluation system for the tutors who are engaged in student work, and gradually expand the ranks of tutors so as to reduce the work intensity of individuals. Then tutors will have time to strengthen their professional quality and comprehensive vision, the work of tutors can meet the needs of students' all-round development and emotional needs gradually.

\subsection{Sufficient Professionals}

As mentioned above, in residential colleges such as Yale and Harvard, dormitories are shared by tutors, wardens, and specialized service staff. in other universities of China, there are also academic tutors, life tutors and other managerial personnel in different positions, which is the guarantee of the operation of the academy system. The individualized training has been proved to play an important role in improving the quality of undergraduates and cultivating excellent talents. But we need to pay attention to the teacher-student ratio, "professional" is not only the concept of knowledge, Tutors should have enough time to communicate with students. In the context of individualized instruction, a mentor should not take on too many students. The mentor's energy is insufficient, and the guidance given to the students will be compromised. However, when quite a number of universities in China implement the academy system, they blindly copy the tutorial system, so that a tutor has to face dozens or even more than 100 students, in addition to sometimes the tasks of teaching and scientific research, it is no different from the situation faced by the head teachers before the reform. It is quite different from the original purpose of the tutorial system, they reduce the reform to mere formalities.

Four Seas College was originally located in the Zhuhai campus of Jinan University and moved to the Panyu campus in Guangzhou in 2014. However, the distance between tutors and students, while most tutors work at the headquarters, makes it difficult to communicate with each other. The distance from the Panyu campus to the headquarters is about 25 kilometers for about 40 minutes' ride. Taking public transport will spend more time for about 1 or 2 hours. Now, of course, we can use a range of communication tools to do this, but the effectiveness of living together is a different matter. Coupled with the high teacher-student ratio, effective communication between teachers and students can be 
difficult to achieve, and basic communication is very little, not to mention the quality of the guidance.

In order to put the academy system into practice, the ratio of teachers to students must be lowered. There are two ways for universities to face it: Building Small and beautiful academies, reducing the number of students, or expanding the ranks of tutors. For example, Yuelu Academy of Hunan University only enrolls 10 to 20 freshmen from the history department each year. Each undergraduate has a tutor, a 1-to-1 student-to-faculty ratio makes it receive good results, the rate of further education of students is high (Xiao \& Pan, 2017) for the second approach, the introduction of the "teaching assistant" system, by excellent graduate students to share some pressure of tutors. After the teachers analyze the students' problem sets, they can comprehensively select students with different personalities, intelligence, learning level, and other aspects. Before class, the teacher focused on guiding students to explain the difficult points, and carefully designed the process of guiding students; After class, the graduate students and the students can encourage each other by filling in the learning evaluation record form. The function of graduate students is not only to guide group members to solve problems, but also as an organizer and supervisor of classroom guidance. Graduate Students may not be knowledgeable and intelligent, but similar ages also make peer-to-peer communication easier.

\section{Conclusion and Prospect}

Any reform will have a period of learning and fumbling process, the friction between new methods and old habits is inevitable. As a new mode of personnel training, the development of the academy system still has a long way to go. At the initial stage of the development of the academy system, colleges and universities should do well in grasping the center of deepening the relationship between teacher and students and students themselves, sorting out the staffing and management methods, positioning themselves clearly, and building the institutional basis for the development of the academy system, the academy system construction can develop well and make a positive contribution to the cultivation of talents.

To observe whether the effect of this system is not just to do some student satisfaction surveys, but it should stand the test of time, constantly improve its shortcomings in practice, and push some corresponding supporting system reform, then many years later, to observe the development of alumni and alumni satisfaction, to determine whether it is good or bad.

\section{Conflicts of Interest}

The author declares no conflicts of interest regarding the publication of this paper.

\section{References}

Cao, H. Q. (2009). College System and the Chinese University of Hong Kong. Contem- 
porary Education Science, 9, 40-43.

He, Y. P. (2016). On the English and German Modes of Higher Education: The Development and Changes of Residential College System in Harvard. Education and Examinations, 2, 87-91.

Huang, H. M. (2010). A Comparative Study of Student Management Modes between College System and Residential College System. Research in Higher Engineering Education, 3, 108-113.

Liu, B. Q. (2010). Yale Humanities Education Research. MASc. Thesis. Baoding: Hebei University.

Liu, X. G. (2017). Research on Cultivating College Sudents' Entrepreneurship under the College System. Jinan: Shandong University.

Qian, M. (2004). Heritage of New Asia. Beijing. SDX Joint Publishing Company.

$\mathrm{Tu}, \mathrm{Q}$. (2013). The Role Reconstruction of College Teachers under the Background of College System. MA.Sc Thesis. Suzhou: Suzhou University.

Xiao, Y. M., \& Pan, B. (2017). Integration of Traditional College Education and Modern University Education: Exploration and Reflection on the Implementation of Undergraduate Tutorial System in Yuelu Academy. University Education Sciences, 2, 40-46 + 124. 